\title{
Challenges and Suggested Approaches for EMI Content Lecturers in the Context of Chinese State Universities
}

\author{
Yilan Xu \\ University of St Andrews, United Kingdom \\ 514401313@qq.com
}

\begin{abstract}
In recent years, an increasing number of universities, especially in the Asian region, have adopted English as a Medium of Instruction (EMI). With the trend of globalization, the spread of EMI in Chinese higher education has grown. This paper aims to assess current challenges confronting Chinese EMI content lecturers in state universities and provide suggestions to address these issues. Through analyzing prior relevant literature, three difficulties that Chinese EMI lecturers encounter are identified: (i) lecturers' English proficiency; (ii) inappropriate pedagogical approach in the EMI context; and (iii) the identity of EMI lecturers in tertiary education. Several solutions are proposed to support teachers implementing EMI courses of high quality.
\end{abstract}

Keywords: English Medium Instruction; Chinese EMI Content Lecturers; EMI in Chinese Tertiary Education; EMI Pedagogy; Teacher Identity.

\section{Introduction}

With globalization and internationalization, English as a medium of instruction (EMI) has increasingly been used in primary to tertiary institutions in worldwide education (Tsou and Kao, 2017). Accordingly, the EMI or bilingual teaching pattern is also highly encouraged in Chinese state universities' popular courses and disciplines. Although EMI development for most Chinese state universities is no more than two decades old, significant progress has been achieved in Chinese higher education, including attracting many international students and well-known scholars, enhancing academic reputation. Nevertheless, various challenges exist in the EMI of Chinese higher education, especially for Chinese EMI content lecturers. Based on the context of EMI in the Chinese university sector, the purpose of this paper is to identify a range of problems that occurred in the implementation of EMI programs and provide practical suggestions. This article attempts to briefly demonstrate the background of EMI construction in Chinese public tertiary institutions, then systematically analyze the challenges that Chinese content lecturers may confront and discuss how these issues can be addressed to deliver effective teaching.

\section{EMI in Chinese Universities}

There is no doubt that the promotion of EMI programs in higher education positively influences long-term development. According to Kim (2107), the advantages of EMI in higher education can be divided into three aspects. First, for individuals, more competitive graduates can be cultivated for employment in the international workplace or the academic area because they can acquire high language proficiency and subject knowledge through EMI. Second, for universities, implementing EMI aims to improve the positions in both domestic and global rankings and facilitate collaborative programs with other very outstanding universities in the world. Third, governments committed to increasing the population of international students to achieve the goal of globalization in higher education. In addition, one of the most significant driven forces that accelerated the uptake of EMI in Chinese higher education is the governmental perception of the massive demand for graduates proficient in the English language because of the 2008 Summer Olympics and WTO ascension (Beckett and Li, 2012). Therefore, with great benefits mentioned above, a historic policy was enacted by the Chinese Ministry of Education (2001, cited in Beckett and Li, 2012) that required around 5\% - $10 \%$ of the leading tertiary courses to adopt English as a medium of instruction to teach (e.g., often 
Volume 3 (2021)

used in information technology, biotechnology, and finance). As a result, as of 2006, 132 out of the 136 state universities in mainland China have offered EMI courses (Beckett and Li, 2012).

\section{Challenges for Chinese EMI Lecturers}

The vigorous development of EMI in the universities has prompted many content lecturers to adopt EMI or bilingual approach. With the context of EMI in Chinese higher education over the last two decades, the Chinese EMI content lecturers confront various challenges and difficulties in their teaching process that need to be justified. First, one of the most significant encounter linguistic obstacles in the course delivery is the low intelligibility and fluency of communication. Zhang (2018) argues that although the lecturers' English proficiency is not crucial in delivering effective EMI teaching, it is indeed a prerequisite. Furthermore, Burns' (2014) study claims that a principal drawback is the content lecturer's language competence can negatively affect students' learning. For instance, the lecturer is likely to feel difficulties coping with the unforeseen situations in class or expressing opinions by paraphrasing, finding words, and refining statements, which possibly results in learners' inadequate acquisition of content knowledge. For some Chinese EMI content lecturers only teaching Chinese students, translanguaging and code-switching can be applied to the pedagogical practice to ensure the instruction quality. In contrast, other Chinese EMI content lecturers teaching international students may find that the appropriate level of linguistic proficiency and communicative ability plays an essential role in effective EMI teaching.

The second challenge for Chinese EMI content lecturers is that whether the current pedagogical approach is appropriate conforming to the core principles of EMI teaching. Generally, there is oneway communication in the monolingual Chinese classroom with few classroom interactions as the lecturer presents the knowledge and illustrates why and how to apply these theories to deal with practical issues. Suppose such a similar pedagogical pattern is adopted in the EMI context, shifting the instructional language from Chinese to English. It can be detrimental to students' learning initiative and the motivation for studying EMI courses. Reeve and Jang (2006) claim that the autonomy-supportive educational practice of the lecturer is a positive factor to promote students' intrinsic motivation for learning. In addition, the pedagogical method Chinese EMI content instructors frequently adapt in the classroom with the local students is translanguaging and codeswitching; both the lecturer and students may naturally search the words in Chinese to communicate when they encounter a communication barrier in English. Most Chinese content lecturers regard translanguaging as an effective scaffolding in the EMI classroom. For students with lower English proficiency, this approach supports enhanced facilitation of content comprehension, and a better rapport and class interaction can be created (Fang and Liu, 2020). However, the appropriateness of such pedagogy is a controversial issue in EMI teaching. According to Kyeyune (2010), the enhancement of students' academic literacies cannot be developed using this pedagogical approach.

Furthermore, as mentioned above, the EMI class constitution in most Chinese public universities is not mixed, which means the local students and international students are taught separately. More importantly, the lecturers and students are non-native English speakers. Hence, another serious challenge in the EMI pedagogy is that besides the language barrier, the international students' attitudes and perceptions on the instructional style of Chinese EMI content lecturers are commonly less positive. Research by He and Chiang (2016) in a national university in southern China discussed how international students view the EMI programs based on their educational experience and thoughts. Some judgment about the pedagogical behavior of Chinese content lecturers is worthy of attention. It pointed out that the international students generally consider the Chinese content lecturer's instruction as a 'problematic' teaching style due to their inadequate language proficiency and the distinct teaching pattern in China. Specifically, the teaching activities emphasize listening to the teacher's demonstration, note-taking, and reading materials rather than sustainable learning abilities such as problem-solving and critical thinking, which results in the EMI class being less 
interactive (He and Chiang, 2016). Therefore, the pedagogy in EMI has a significant impact on the student learning experience.

Another challenge for the Chinese content lecturer is the cognition and beliefs regarding identity in the tertiary EMI context. Kim (2013) argues that the awareness of teachers' identity construction and its significant impact on cultivating students' identity is equally important as the academic knowledge developed. Whether the EMI teachers are native speakers (NS) or non-native speakers (NNS) of English are extensively discussed, and such preference for the teachers also exists among Chinese students. Compared with local teachers, most Chinese parents and students are convinced that NS teachers are professionals who possess particular expertise in language proficiency and content mastery in the international academic field. Therefore, it adversely affects the NNS content lecturer's confidence and their teaching career in EMI. Nevertheless, a recent study about EMI lecturers' characteristics and student desires shows that the NS lecturer is not necessarily the preferred choice. Instead, in addition to the high proficiency in linguistic competence and content knowledge, the more popular lecturers can effectively deliver the course with professional pedagogy and a good command of the students' first language and the local culture (Inbar-lourie and Donitsa-schmidt, 2020).

Apart from the previous issue stated, the NNS Chinese EMI content lecturer is also frustrated with identity recognition in terms of language instruction. On the one hand, some content lecturers refuse to be responsible for students' linguistic problems even though they understand the detrimental impacts on learning from the lack of academic English tutoring in the EMI context. Therefore, the EMI content lecturer's attitude towards the role of the language teacher is strongly negative. Meanwhile, unlike most western universities providing academic English service to students, the academic English support is deficient in Chinese higher education (Beckett and Li, 2012). Therefore, from Chinese students' perspectives, the content lecturer must help students overcome the linguistic difficulties by supplementing the extra language support in class. However, the content lecturer should focus on the subject instruction because the support for students' English proficiency is beyond the teachers' abilities, considering other factors involving the workload, time-consuming, and lack of professional training (Galloway and Ruegg, 2020). On the other hand, for some students with lower English proficiency who cannot catch up with the instructional progress, the lecturer would decrease the interaction opportunities because there is no expectation of student participation ( $\mathrm{Hu}$, 2019).

\section{Chinese EMI Lecturers}

Given the analysis discussed previously, the Chinese content lecturers confront multiple difficulties in the EMI implementation. Therefore, to deliver effective EMI teaching, the university and content lecturers should adopt several strategies and solutions to address these issues.

Firstly, to create a high-quality language environment for the international learning experience, an English language requirement entry should be set for EMI content lecturers and students to ensure adequate linguistic competence for classroom interaction and in-depth discussion of content knowledge. According to $\mathrm{Hu}$ (2019), if there is no high proficiency in the instructional language, the lecturers can fail to engage students in the comprehensive cognition of content acquisition by scaffolding the mastery of complex subject knowledge. Similarly, it is difficult for students to construct the content knowledge framework systematically through EMI learning without competent English linguistic abilities. In addition, besides the language proficiency requirement, the teaching qualifications and certificates are also necessary as the basic standards tor EMI content lecturers because it reflects the minimum level of pedagogy. Meanwhile, the university EMI program can arrange a trial lecture to examine English linguistic competence and pedagogical skills during the hiring process.

Secondly, the university can offer lecturers with little teaching experience in EMI education opportunities to attend professional development programs. Based on research on teachers' 
perceptions of professional development training for EMI (Fenton-smith, Stillwell, and Dupuy, 2017), the CPD training can facilitate the acquisition of new technologies, language and communication skills, and pedagogical approaches to building effective EMI classrooms are considered most important. Dafouz (2018) notes that the CPD program for EMI content lecturers is beneficial for equipping them with crucial abilities to be confident dealing with the diverse and international teaching context. However, the arrangement related to professional training programs is not compulsory and obligatory for the lecturers because their time is occupied with a heavy workload on teaching and academic research. Incentives should be introduced to encourage professors and lecturers to participate in EMI professional training. There are also few references about the pedagogy on the effectiveness of EMI course teaching to provide training support.

In addition, to address the issue concerning the Chinese EMI content lecturer's anxiety of the identity as a NNS, and the uncertainty of the role as a language teacher, universities should promote collaboration between NS teachers and content teachers. Learners' English ability in academic literacy significantly influences the further achievement of academic content study. The modes of collaboration between the content teachers and NS teachers can be based on students' learning needs and NS teachers' instructional demands (Trent, 2010). For instance, considering enhancing students' input in the content and language, the NS teacher can help the content teacher design the teaching curriculum and materials and offer instructional language strategies to cope with the international classroom. However, the major constraint of this teamwork for both parties is that it is unusual for professors who are experts in their respective research areas to engage in cross-departmental collaboration. Simultaneously, another major drawback of cooperation is time. Besides teaching, lecturers prioritize conducting academic research and publishing articles because of the traditional promotion mechanism of tertiary education (Dearden, 2018). Therefore, compared with lecturers' pressures in teaching and researching, the lack of motivation and benefits is likely to make it challenging to foster collaboration between EMI content lecturers and college NS lecturers. Moreover, despite the EMI content, lecturers generally expect to avoid dealing with language problems. Yet, the advantages of team teaching pattern under the EMI context is worth highlighting, which can contribute to EMI course implementation and improve the undergraduate learning experience (Lasagabaster, 2018).

Another significant aspect of improving the EMI content lecturers' motivation to implement the course effectively is that the lack of incentives and the need to change the promotion system. The study regarding Chinese content lecturers' perceptions of EMI professional development in Chinese higher education found that the aspiration to dedicate time and cost to pursue specific pedagogical and linguistic competence improvement to obtain a certificate is relatively negative. Teachers think there is no strong motivation supporting them to complete teacher training; the vague evaluation and promotion policies implemented by the relevant government and university departments are insufficient (Macaro and Han, 2020). Hence, the institutional departments should cover the expense of EMI teaching training programs for EMI content lecturers. After all, the university benefits the most by acquiring excellent content lecturers with well-known certifications and the admirable prestige they bring in the higher education field.

\section{Conclusion}

The previous analysis of various challenges and difficulties that Chinese EMI content lecturers may confront in Chinese State universities can be shown in three dimensions. The first challenge for Chinese content lecturers is their insufficient English linguistic and communication proficiency, which is likely to negatively influence the effective EMI course delivery. Meanwhile, the frequent use of translanguaging and code-switching strategies does not favor learners' academic literacy in English. The second challenge for Chinese content lecturers is that the traditional Chinese instructional pedagogy that is teacher-centered with little students engagement and classroom interaction is inconsistent with the core principles of EMI education. Moreover, especially in the 
international class, it is disadvantageous to students' learning enthusiasm and autonomy, leading to a disappointing learning experience. Finally, another challenge for the Chinese EMI content lecturers is the lack of confidence in their identity as NNS of English and the reluctance to act as a language teacher in the EMI classroom.

Several solutions are proposed to address the issues discussed above to enable Chinese content lecturers to implement EMI courses effectively. The initial solution is that the English language requirement entry should be set for both EMI content lecturers and students to ensure adequate linguistic competence for classroom interaction and in-depth content discussion. Also, a trial lecture is recommended for the employer to assess the applicant's language and pedagogical competence. Furthermore, to facilitate Chinese content lecturers' pedagogy in EMI, the university can provide opportunities and funding for lecturers who have little teaching experience in EMI education to attend the professional development programs. Collaboration between NS of English teachers and content teachers should be promoted to improve instruction quality and students' English competence in academic subject learning. Additionally, the authority and university should remedy the evaluation and promotion mechanism to motivate Chinese EMI content lecturers devoted to effective EMI teaching.

\section{References}

[1] Beckett, G. H. \& Li, F. (2012) 'Content-based English education in China: Students' Experiences and perspectives', Journal of Contemporary Issues in Education, 7 (1), pp. 47-63.

[2] Burns, A. (2014) 'English as a medium of instruction: Challenges for Vietnamese tertiary lecturers', Journal of Asia TEFL, 11 (3), pp. 1-31.

[3] Dafouz, E. (2018) 'English-medium instruction and teacher education programmers in higher education: Ideological forces and imagined identities at work', International Journal of Bilingual Education and Bilingualism, 21 (5), pp. 540-552. doi:10.1080/13670050.2018.1487926.

[4] Dearden, J. (2018) 'The changing roles of EMI academics and English language specialists', in Kırkgöz, Y. and Dikilitaş, K. (eds), Key Issues in English for Specific Purposes in Higher Educations, Cham: Springer, pp. 323-338. doi: 10.1007/978-3-319-70214-8_18.

[5] Fang, F. and Liu, Y. (2020) "“Using all English is not always meaningful”: Stakeholders' perspectives on the use of and attitudes towards translanguaging at a Chinese university', Lingua, 247, p. 102959. doi: https://doi.org/10.1016/j.lingua.2020.102959.

[6] Fenton-smith, B., Stillwell, C. and Dupuy, R. (2017) 'Professional Development for EMI: Exploring Taiwanese Lecturers' Needs', in Fenton-Smith, B., Humphreys, P., and Walkinshaw, I. (eds), English Medium Instruction in Higher Education in Asia-Pacific. Cham: Springer, pp. 195-217. doi: 10.1007/9783-319-51976-0_11.

[7] Galloway, N. and Ruegg, R. (2020) 'The provision of student support on English Medium Instruction programmes in Japan and China', Journal of English for Academic Purposes, 45, p. 100846. doi: 10. 1016/ j. jeap.2020.100846.

[8] He, J. J. and Chiang, S. Y. (2016) 'Challenges to English-medium instruction (EMI) for international students in China: A learners' perspective', English Today, 32 (4), pp. 63-67. doi: 10.1017/S026607841 6000390.

[9] $\mathrm{Hu}, \mathrm{G}$. (2019) 'English-medium instruction in higher education: Lessons from China', Journal of Asia TEFL, 16 (1), pp. 1-11. doi: 10.18823/asiatefl .2019.16.1.1.1.

[10] Inbar-Lourie, O. and Donitsa-Schmidt, S. (2020) 'EMI Lecturers in international universities: Is a native/non-native English-speaking background relevant?', International Journal of Bilingual Education and Bilingualism, 23 (3), pp. 301-313. doi: 10.1080/13670050.2019.1652558.

[11] Kim, E. G. (2017) 'English medium instruction in Korean higher education: Challenges and future directions', in Fenton-Smith, B., Humphreys, P., and Walkinshaw, I. (eds), English Medium Instruction in Higher Education in Asia-Pacific. Cham: Springer, pp. 53-69. doi: 10.1007/978-3-319-51976-0.

[12] Kim, Y. M. (2013) 'Teacher identity as pedagogy in an EMI course at a Korean university', English Teaching, 68 (3), pp, 85-107. 
Volume 3 (2021)

[13] Kyeyune, R. (2010) 'Challenges of using English as a medium of instruction in multilingual contexts: A view from Ugandan classrooms', Language Culture and Curriculum, 16 (2), pp. 173-184. doi: 10. 1080/ 07908310308666666.

[14] Lasagabaster, D. (2018) 'Fostering team teaching: Mapping out a research agenda for English-medium instruction at university level', Language Teaching, 51 (3), pp. 400-416. doi: 10.1017/S0261444818000 113.

[15] Macaro, E. and Han, S. (2020) 'English medium instruction in China's higher education: Teachers' perspectives of competencies, certification and professional development', Journal of Multilingual and Multicultural Development, 41 (3), pp. 219-231. doi: 10.1080/01434632.2019.1611838.

[16] Reeve, J. and Jang, H. (2006) 'What teachers say and do to support students' autonomy during a learning activity', Journal of Educational Psychology, 98 (1), pp. 209-218. doi: 10.1037/0022-0663.98.1.209.

[17] Trent, J. (2010) 'Teacher identity construction across the curriculum: Promoting cross-curriculum collaboration in English-medium schools', Asia Pacific Journal of Education, 30 (2), pp. 167-183. doi: $10.1080 / 02188791003721622$.

[18] Tsou, W. and Kao, S. (2017) 'Overview of EMI Development', in Tsou, W. and Kao, S. (eds), English as a Medium of Instruction in Higher Education. Singapore: Springer, pp. 3-18. doi: 10.1007/978-981-JO4645-2.

[19] Zhang, H. (2018) 'What makes an effective English-medium course in China? Experiences and perspectives of international Undergraduates', RELC Journal, 49 (3), pp. 353-368. doi: 10.1177/ 00336 88217691815. 